\title{
PA700 Regulatory Module
}

National Cancer Institute

\section{Source}

National Cancer Institute. PA700 Regulatory Module. NCI Thesaurus. Code C13336.

Ubiquitinated proteins are degraded by a 26S ATP-dependent protease complex, composed of a 205 catalytic proteasome and two 195 PA700 regulatory modules. The multi-subunit PA700 complex binds two sites of the $20 \mathrm{~S}$ proteasome and is composed of at least six related ATPases and approximately fifteen non-AT Pase polypeptides. Each of the ATPases, PSMC1-6, contains an AAA (ATPases associated with diverse cellular activities) domain. A protein complex containing p42 and p50 enhances PA700 activation of the proteasome. 